\title{
A phyto-climatic transect in the Alpes Maritimes used to characterize the northern limit of the Mediterranean biogeo- graphical area
}

\author{
Julien Andrieu*', Florent Lombard', Matthieu Vignal', Michel Godron² \& Frédéric Alexandre ${ }^{3}$
}

${ }^{1}$ University Côte d'Azur, UMR ESPACE, 98 boulevard E. Herriot, 06204 Nice cedex 02, France; email: florent. lombard@univ-cotedazur.fr

${ }^{2}$ CNRS, La Graineterie, 18410 Brinon sur Sauldre, France; email: migodron@wanadoo.fr

${ }^{3}$ University Paris13, EA Pleiades, 99 Avenue Jean Baptiste Clément, 93430 Villetaneuse, France; email: alexandre@univparis13.fr

${ }^{*}$ Corresponding author, email: julien.andrieu@univ-cotedazur.fr

\begin{abstract}
This paper aims, with a botanical transect, to contribute to define the boundary between the Mediterranean biogeographical area and the flora of the Alpine domain. The transect, realized in 2018, is located in the Maritimes Alps, in the Roya Valley at the northernmost limit of the Mediterranean in contact with a mountain ecoregion. Our objective was to get as close as possible to the integral flora (Tracheophytes), that counts a corpus of 529 species. A $40 \mathrm{~km}$ long transect divided in 150 sampling sites led to 7333 observations of presence, analyzed by Factorial Composant Analysis (FCA) and frequency analysis. Statistics revealed a significant distinction of two floras with a clear spatial boundary not crossed by $76 \%$ of the species. The Transect revealed a clear biogeographic limit of biogeographical area, which seems to converge well with the limit of the Mediterranean Hotspot as defined by Myers (2000).
\end{abstract}

KEY WORDS Phyto-climatic transect; Biogeography; Mediterranean; Hotspot; Biogeographical areas.

Received 07.04.2020; accepted 01.07.2020; published online 26.08.2020

\section{INTRODUCTION}

Defining biogeographical areas is a major scientific issue (Myers, 2000, Olson et al., 2001; Cox, 2001; Mackey et al., 2008; Hattab et al., 2015), especially for plants, which are less often taken into consideration when delineating these boundaries (Kier et al., 2005). However, the main challenges for biodiversity conservation caused by mass extinctions (Godet \& Devictor, 2018) and the impact of climate change (Molinos et al., 2018) are a major requirement for this, whether in terms of biogeographical division of the planet (Good, 1947; Takhtajan, 1986) or because of the needs of identi- fying particular biogeographical structures. For example, the work of Myers (1990) on defining biodiversity hotspots remains a major reference, as more recent works on hotspots overall have merely characterized or subdivided them (Médail \& Quézel, 1997; Olson et al., 2001).

The definition of biogeographic areas also involves a precise, spatial examination of their boundaries (Ferro \& Morrone, 2014; Morrone, 2018). An object can only be mapped accurately by validating its boundary. The boundary of a biogeographic area combines the boundaries of specific distribution areas. These rarely coincide with one another and area boundaries appear as forms of more or less 
gradual transitions (Whittaker, 1967; Ferro \& Morrone, 2014). Making a detailed examination of the limits of specific distributions at the edges of biogeographical areas is also a particularly topical objective to understand the impact of climate change on species distribution (Molinos et al., 2018).

One of the characteristics of the Mediterranean area is that a major part of its boundary coincides with mountain ranges. These mountain ranges can be floristic provinces (Alps, Atlas Mountains) and sometimes they separate two distinct bioclimatic areas as a result of a climatic barrier effect (Cevennes, Ligurian Alps). Thus, defining the limit of the Mediterranean area requires placing the boundary between the Mediterranean mountains (high-altitude Mediterranean flora) and those at its periphery (non-Mediterranean flora). This could also appear as a matter of scale because the Mediterranean area was considered a kingdom in the same way as the Circumboreal region (Takhtajan, 1986), while the Alps a smaller subdivision only. However, a more recent work (Condé \& Richard, 2002) places within Holarctic Kingdom both Mediterranean and Alps as regions of the same level. The Alps are defined as an area in classifications subdividing provinces based on an ecological approach as the Ecoregions (Olson et al., 2001). Here, we will refer to the Alpine area as being a part of the Central European region.

The Mediterranean biogeographical area has been defined and redefined over the centuries (Quézel \& Médail, 2003). The inclusion of the Mediterranean area in Myers' list of hotspots and the production of a map disseminated as georeferenced and open-access files have helped to set this limit for research work and for territorial biodiversity management tools. However, this limitation of the Mediterranean hotspot and the Mediterranean biogeographical area still raises a number of questions:

- How are the species boundaries between the Mediterranean and the Alps spaced out in this area where one goes from the coastline to an altitude of 2,500 meters within a distance of just 40 kilometers?

- Does a significant limit appear? With what regeneration rate of the flora on both sides?

- Is there a transition by impoverishment or by overlap?

- Is the limit of the biodiversity hotspot the limit of the Mediterranean biogeographical area? What is its level of spatial accuracy?

The development and increasing accessibility of large natural history or environmental databases has fostered a large majority of research programmes on biogeographical areas to develop tools for spatial analysis (classification or clustering of species, statistical characterisation of the specific patterns of pre-established regions, biodiversity hotspots or ecoregions), or the investigation of phenological variability by means of satellite imagery.

This paper relies on an original and ad-hoc field study carried out to help validate these spatial approaches to area boundaries. The naturalistic approach in the field necessarily reduces the scale of analysis when time, financial and human resources are limited, but the discussion will aim to refocus the regional terrain in a global, or at least Mediterranean, perspective, albeit, which - from a methodological standpoint - will deal with the boundaries of the areas as a whole.

Several significant regional transects have been conducted since the 1990s and 2000s to identify the Mediterranean area boundary (Alexandre, 1994; Génin, 1995; Alexandre et al., 1998a; Alexandre et al., 1998b; Godron \& Andrieu, 2013). This work has made it possible to demonstrate that flora varies as a continuum without clear limits common to several species. This pattern was expected as long as it had been encountered for all other 4 transects around the northern limit of the Mediterranean area in France.

In addition to all this research, a transect was carried out in spring 2018 in the Roya valley, shedding light on the Mediterranean area boundary, which is unique because it is at one of the northernmost points of the area boundary among the Mediterranean-mountain contacts. It is one of the places where the climatic contrast is higher.

It thus contributes to define the boundary between the Mediterranean and Alpine biogeographical areas. So far, botanical investigations in the region have largely focused on overlapping floral species. For example, it is frequently pointed out that one can find Holm oaks (Quercus ilex) and Silver firs (Abies alba), which are considered to belong to very different habitats, regularly together. In addition to the continuum without clear limit, the expected pattern was a large overlap between Mediterranean and alpine Floras. 


\section{MATERIAL AND METHODS}

\section{Data collection}

Gao \& Kupfer (2018) demonstrated that a biogeographic regionalization must be based on spatially explicit methods and not only on ecological ones. We chose the "systematic random" transect sampling method, in which the samples are consecutive linear segments of equal size. As in every sampling, this spatial sampling should make it possible to test any hypothesis of variation modality. For effective sam- pling, the transect must be oriented to be as heterogeneous as possible (Alexandre et al., 1998a). It was therefore to be oriented along a north-south axis where the altitudinal, and therefore climatic, gradient is the highest since it runs from the seafront to the crest line separating France and Italy (Fig. 1).

Sampling must then provide for the evaluation of the spatial variation patterns, which requires, on the one hand, a regular and continuous grid and, on the other hand, an adapted scale allowing to finely describe the variation without anthropic or edaphic microvariations prevailing over biogeographic con-



Figure 1. Map of transect location and boundary of the Mediterranean Hotspot. 
siderations. Segments of $250 \mathrm{~m}$ by $10 \mathrm{~m}$ were therefore arranged in sequence along the entire transect. However, we cancelled a few segments where anthropogenic activities are too strong for proper biogeographical analysis.

Our objective was to get as close as possible to the integral flora. For this purpose, we recorded the presence of all the species identified to constitute the largest possible corpus. However, our aim was not to identify and list species exhaustively and certain taxa were excluded for some reasons like:

- Some non-flowering species could not be identified with certainty at the time of the year when the sampling took place (e.g., Gallium).

- Some taxon was recorded as lacking effective morphological criteria for identification (e.g., $\mathrm{Hi}$ eracium).

- All green flowering monocotyledons were excluded from the study (Poaceae, Cyperaceae, Juncaceae).

Some taxa are not included due to a lack of information but the corpus of 529 species is rich enough for an original data collection. All statistics have been repeated with all species and without a set of species that might contain identification errors. Results have been very consistent, therefore, the dataset is considered as robust enough. The nonnative species have been observed and included in the statistics. If native species only are usually used for biogeographic studies, we decided to describe flora as it has been observed not as it should be according to past models. The transect was carried out between April 1st and August 1st, 2018 and 150 segments of 250 meters were chained together. Only 6 samplings could not be carried out due to the overly artificial environments. Therefore, they range from 1 to 156 with missing numbers to respect the range-distance numbering. We identified 529 species and compiled 7333 observations.

\section{Spatial analysis methods}

Three indicators of floristic variation in space will be put into perspective: the coordinates of axis 1 of the Factorial Correspondence Analysis (FCA), the area/species curves and the optimal limit.

\section{The FCA and its derivatives}

The first step in the statistical analyses was a
FCA directly on the presence-absence data table. The eigenvalues of the first two axes are $12.4 \%$ and $6.6 \%$. The factorial plane describes the main contrasts in the scatter plot. The first main component here is that which characterizes the biogeographic contrast under study.

\section{The species-area curve}

The species-area curve reflects the increase in number of species as the exploration effort progressed. It is calculated along the transect in both directions.

\section{Structural analysis: the spatial aspect of frequency analysis}

Frequency analysis highlights the significant features of frequency distributions within a set of ecological observations. It is based on the exact probability that each frequency distribution of a characteristic phenomenon will appear, such as the coexistence of two species in all the locations observed, wherever one species appears in each class of ecological descriptor such as altitude, etc. Structural analysis is a part of frequency analysis and focuses on the spatial distributions of ecological observations. The spatial distributions are here examined by the optimal limit. It is a measure of the homogeneity of the two transect sections located on either side of each of the "transitions" between two consecutive segments (between the first and second segments, between the second and third segments, etc.) and thus highlights the most remarkable transitions, which provide the most information.

To discuss the validity of the transect results beyond the simple case of a field study, we conducted a valley-wide survey with the same objective but based on the Mediterranean National Botanical Conservatory's SILENE Database using a cartographic approach. SILENE (Système d'Information et de Localisation des Espèces Natives et Envahissantes, or information and location system for native and invasive species) is a database of floristic observations made by the Mediterranean National Botanical Conservatory. Each geolocated observation of a species can be downloaded, and all the observations of a territorial entity as well, as was the case here. The surveyed territory included the French communities of the Roya Valley and those 


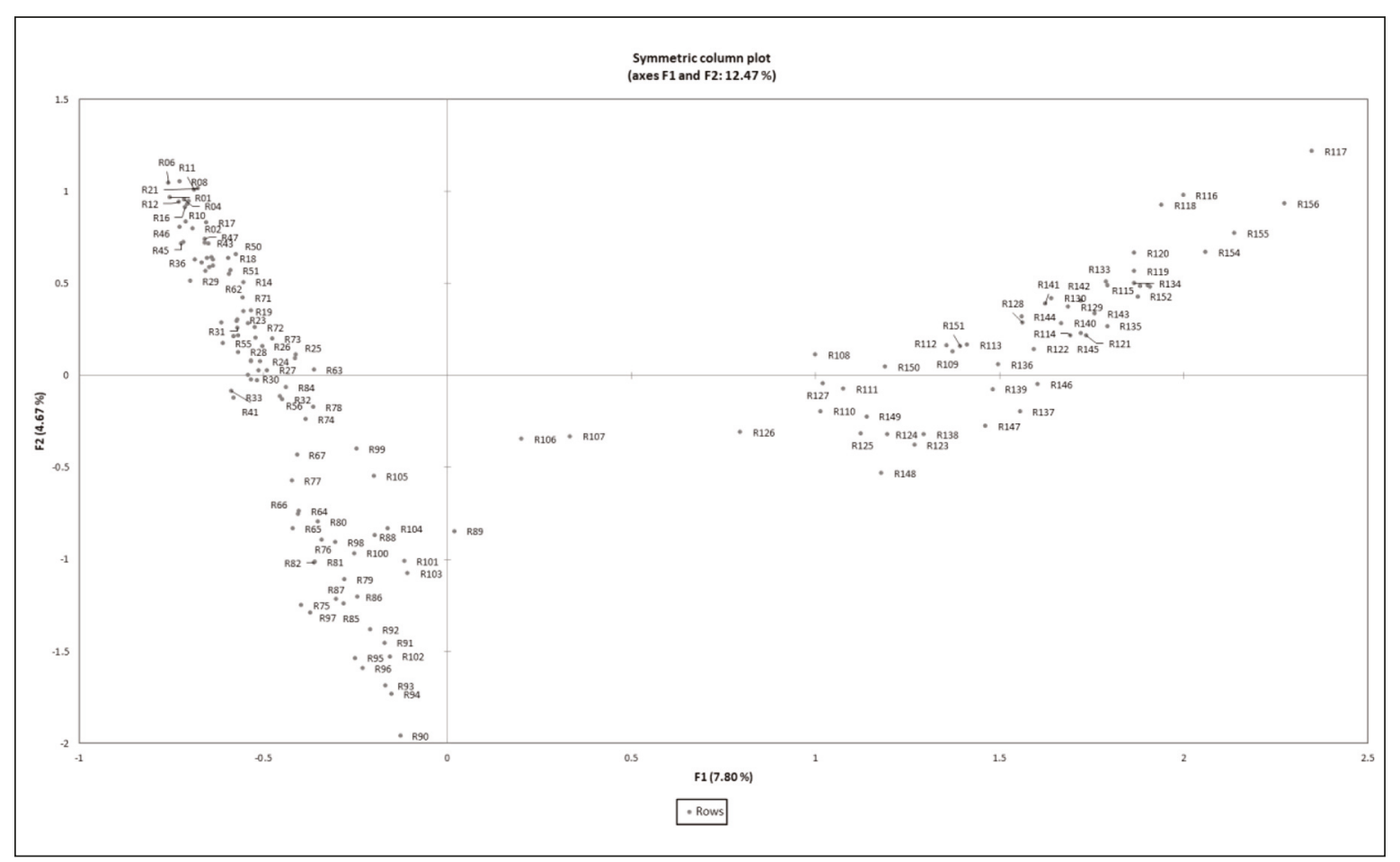

Figure 2. 1/2 factorial plane derived presence-absence data table.

bordering it west of the French-Italian border. We made 100,000 observations of 2,841 taxa (species or subspecies). First, we drew a grid of $400 \mathrm{~m}$ x 400 $\mathrm{m}$ across the whole Roya Valley and a similar area across a strip of land over French communities equivalent to the upstream Italian section to cover the same gradient to the sea. We constructed a presence-absence table based on the grid in a similar way to that of the transect. We performed a Factorial Correspondence Analysis on this data table. An unsupervised K-means classification into 2 classes was also produced. It locates the area boundary between sampling sites 107 and 108 of the transect (Fig. 5). An SQL selection allows to count the species of three distributions: present only in the Mediterranean area; present only in the Alpine area; and lastly in both areas, as defined by the K-mean classification.

\section{RESULTS}

\section{The FCA}

The $1 / 2$ factorial plane (Fig. 2) differs from those usually carried out on this type of data by a strong discontinuity between two groups of sampling sites, which shows that there are two distinct types of sampling sites when seen from a floristic point of view. The absence of individuals in the sampling sites at coordinates close to the origin was equally significant. A few variables (species) are visible in the centre of the $1 / 2$ factorial plane.

Furthermore, a careful examination revealed that the two groups of sampling sites are very clearly structured spatially, since all the those to the south (from segment 1, a sampling site on the coast to number 106 by the adret slope of the Cairos valley, at 1500 meters altitude) are in the Mediterranean group on the left with negative values or close to the origin. All the sampling sites to the north (from 108 to 156, at Pointe du Sabion at 2500 meters altitude) are in the Alpine group on the right. Only sampling sites 106 and 107 appear to be a very short transition between the two biogeographic features. There is an obvious relationship between altitude and first axis coordinates (Fig. 3)

The second axis is a classification of the sampling sites of these two groups separating the open environments in positive values and the forest en- 


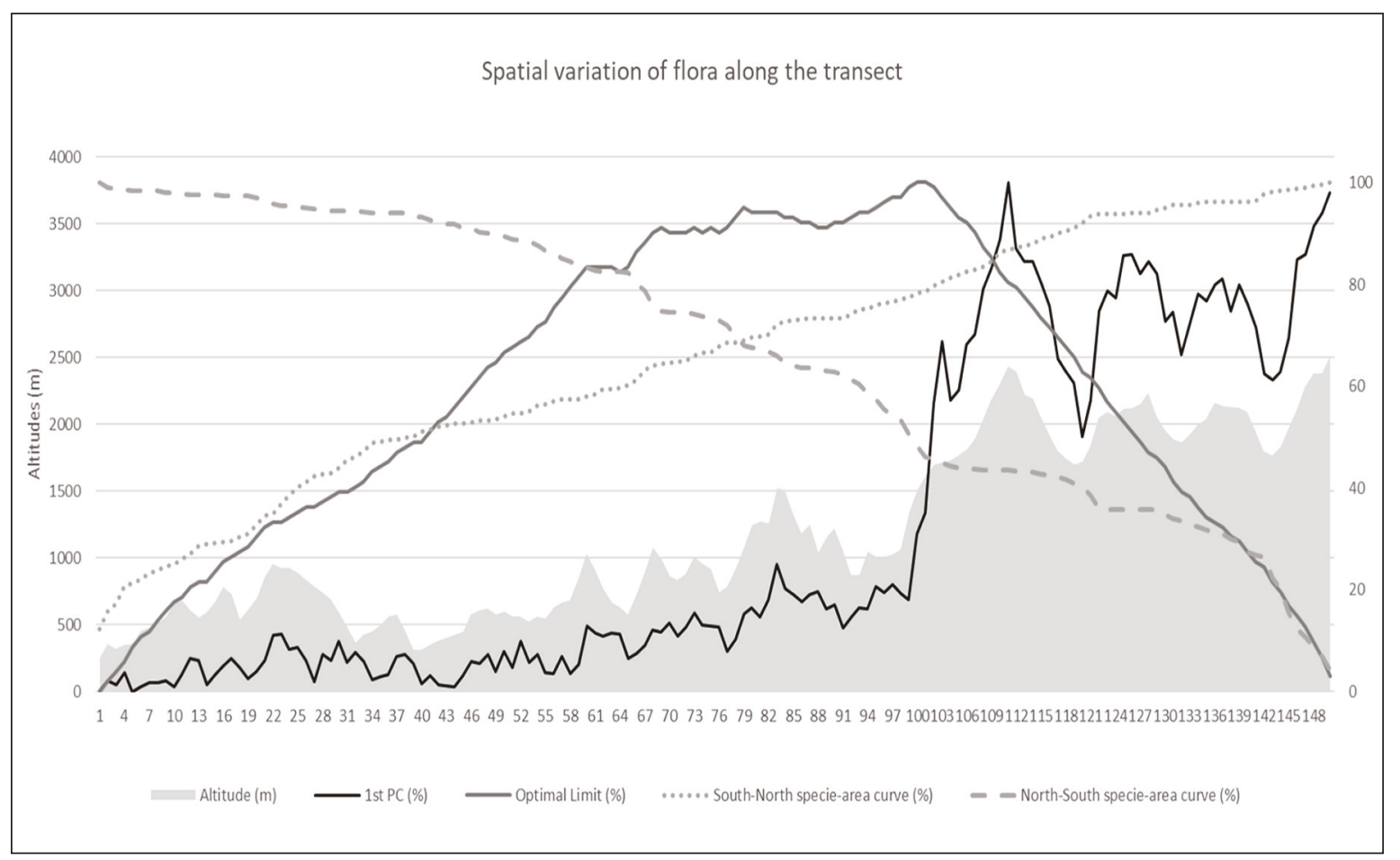

Figure 3. Spatial variation of flora along the transect.

vironments in negative values. The positive sampling sites on axis 2 and those negative on axis 1 correspond to matorrals and are associated with the most strictly heliophilic Mediterranean species (Calendula arvensis; Coronilla valentina; Medicago polymorpha; Crepis vesicaria; Cuscuta epithymum) or thermophile exotic species (Opuntia ficus-indica; Oxalis pes-caprae). The positive sampling sites on axis 2 and those positive on axis 1 correspond to the Alpine pastures and summits and are associated with the most strictly heliophilic Alpine species (Saxifraga oppositifolia, Ranunculus pyrenaeus, Draba dubia, Adenostyles leucophylla, Minuartia sedoides, Draba aizoides, Petrocallis pyrenaica, Leontopodium nivale).

To facilitate a graphical interpretation of these 3 indicators, all have been expressed in percentages with $0 \%$ assigned to the minimum value and $100 \%$ to the maximum value of the indicator.

Figure 3 relates these patterns to the altitude along the transect. The coordinates of axis 1, south of the transect at fairly low elevations, vary little in the form of 100-meter scale microvariations with a very slight slope of the whole between values ranging from 0 to $15 \%$ for the first 55 sampling sites and between 10 and $25 \%$ up to sampling site No. 105 . The curve then slopes extremely steeply with sampling sites 106 and 107 having intermediate values and 108 very high values. Beyond this threshold, the coordinates vary greatly according to altitude, with values between 50 and $70 \%$ for mountain valleys and between 80 and $100 \%$ for peaks and ridges. The first factorial axis has a correlation of 0.98 with altitude. However, it is worth noting that in the first 2/3 (Mediterranean) of the transect, axis 1 varies less than the altitude, while in the last third (Alpine), axis 1 varies more strongly than the altitude.

\section{Species-area curves}

The two species-area curves are almost linear, but there are some slight differences.

The species-area curve from north to south shows a rapidly increasing richness of Alpine species over about ten sampling sites. The trend slows down to reach a threshold around 15 sampling sites and then increases again with a few species before the threshold of the Alpine range consolidates with $40 \%$ of the flora found in the 30 northernmost 
site. A major threshold is reached again, on this same slope of the Cairos valley, from sampling sites 106 and 107 , where a $20 \%$ increase of the flora occurs in ten samplings. Then, a series of small thresholds show a flora enrichment until reaching a $90 \%$ flora level in 110 sampling sites where the curve gently slopes down to the coast. So there is a clear delineation of the Mediterranean flora at sampling site No. 107 on the slope of the Cairos valley as highlighted by the first 3 indicators. From south to north, the species-area curve is much less contrasted. The slope is quite steep to the south of the transect with the 50\% flora level reached in 35 samplings. The slope bends somewhat gradually to reach $95 \%$ of the flora level at sampling site No. 125 before gaining the last 5\% within 3 small thresholds. While the Mediterranean flora is well delimited here with very typical flora delimited by the convergence of the 3 indicators, the species-area curve from south to north shows that the Alpine flora is not a clearly defined and homogeneous flora, except by contrast to the Mediterranean flora. This may be explained by the small number of high-mountain samples and the variability of the flora between mountain forests and Alpine pastures.

\section{The optimal limit}

The optimal limit confirms and quantifies the clear separation of the two floras with a curve that increases with a few steps until it reaches its maximum value for the same transition zone between samples 106 and 107, which constitutes the optimal limit between two biogeographic entities.

\section{Specific richness}

The variation in species richness along the transect adds to this interpretation. The number of species is usually greater than 50 in the first 100 samples and then quite lower in the higher altitudes. The variation in the number of species drops rather significantly on either side of the transition between samples 107 and 108. The greatest range of low species richness samples is to be found between samples 107 and 122 (always less than 40). This confirms that the transect reflects a shift from an area with a Mediterranean endemism (and exotic species) in contact with Alpine flora and that this contact occurs by impoverishment and not by an overlap of the two flora.

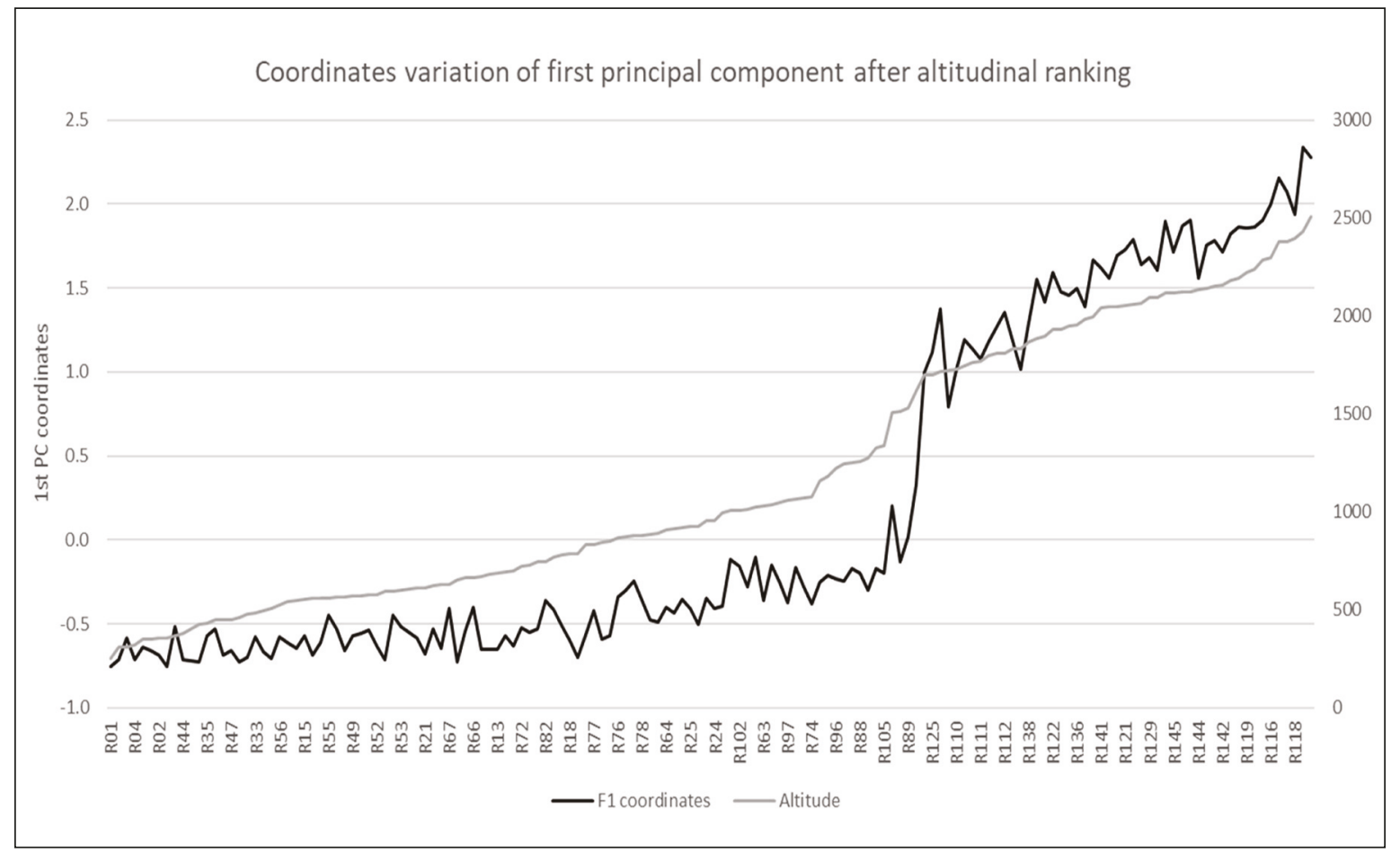

Figure 4. Altitude variation of axis 1 . 
The classification of the surveys by altitude rank (Fig. 4) shows that all the altitudes were sampled, even if the sampling effort, in fact, is somewhat weak around 1300 meters. At around 1650 meters, the curve takes a very steep slope to reach the higher values (Alpine flora). The break in floristic continuity, as seen from a spatial point of view (Fig. 3 ) between samples 106 and 107, converges with that in floristic continuity as considered from an ecological standpoint around altitudes between 1500 and 1600 meters.

The detailed examination of samples 89 and 90 is interesting. The altitudes are quite high (1510-1530 $\mathrm{m})$, higher than the next 16 sampling sites and this altitude is only found on sites 105 and 106. Furthermore, samplings 89 and 90 are a summit and northfacing slope while sampling sites 105 and 106 are on the adret side. A strictly ecological interpretation would lead to expect more Alpine flora for sample sites 89 and 90 than for 105 and 106, but the type of flora is actually much more Mediterranean. This could lead us to infer that the spatial boundary (100 samples in the south and 50 in the north) is stronger than the ecological boundary on either side of an altitude or its corresponding thermal conditions.

A detailed examination of the species distributions in relation to this boundary shows that if the transect is split in two, between samplings 107 and 108,115 species are found only im the north and 287 species only south of the boundary. Therefore, $76 \%$ of the species are related to the boundary, which is a particularly high rate (Tables 1,2$)$.
The validation by a close analysis, on all the SILENE points (see supplementary material) validates that the flora changes rapidly at the level of the 107 survey, generalises the limit between the two biogeographical sets at the valley scale and quantifies, on a cartographic basis, with more species, that $52.6 \%$ of the species are only restricted to the Mediterranean part, accompanied by $10.1 \%$ of species only restricted to the Alpine part.

\section{DISCUSSION}

The main result of this statistical analysis of the transect is the clear-cut boundary that separates the Mediterranean flora that appears homogenous and the Alpine flora that appears less homogenous with an altitude-dependent variation quite related to a differentiation between forest flora and grassland flora.

However, this result is only of interest in biogeography if it is valid on smaller scales. The transect was deliberately located at the contact zone between the Mediterranean area and the Alpine chain where the gradient is strongest. The transect goes from sea level to 2600 meters in $40 \mathrm{~km}$. Its configuration comprise a topographic leap, since the slope of the Cairos separates the valley bottom (at $870 \mathrm{~m}$ ) and the summit of the Corne de Bouc (at $2430 \mathrm{~m}$ ) in only $5 \mathrm{~km}$, i.e., 20 segments of the transect. One may quite reasonably assume that these topographic features induced an increased contrast

\begin{tabular}{|c|c|c|c|c|}
\hline & North only & South only & Common & Total \\
\hline Species richness & 115 & 287 & 127 & 529 \\
\hline Percent of total & 21.7 & 54.3 & 24 & 100.0 \\
\hline
\end{tabular}

Table 1. Species distribution by transect range limit.

\begin{tabular}{|c|c|c|c|c|}
\hline & North only & South only & Common & Total \\
\hline Species richness & 287 & 1494 & 1060 & 2841 \\
\hline Percent of total & 10.1 & 52.6 & 37.3 & 100.0 \\
\hline
\end{tabular}

Table 2. Species distribution according to area limit on the SILENE dot grid. 
and that a transect a few hundred meters further east or west, where this difference in elevation would have been spread out over a greater distance, would have been less contrastive.

However, a second analysis discussed in the supplementary material section made it possible to carry out a presence-absence FCA over the whole Roya valley and not only along a sampling line. This provides an overview of the transition to high mountains in this valley. The unsupervised classification of the FCA coordinates locates the boundary in the same area as the transect and thus broadens it to the whole valley. We can see two rather compact entities, although a few islands and enclaves appear. The SQL selection for quantifying species that do not cross the line reveals lower rates than those of the transect (62.7\% versus $76.4 \%)$. This proves the transect to be drawn in the most contrasted area. This was the original intention supporting this sampling choice. However, although the total volume is lower, it is still clear that the limit coincides spatially and that the rates of

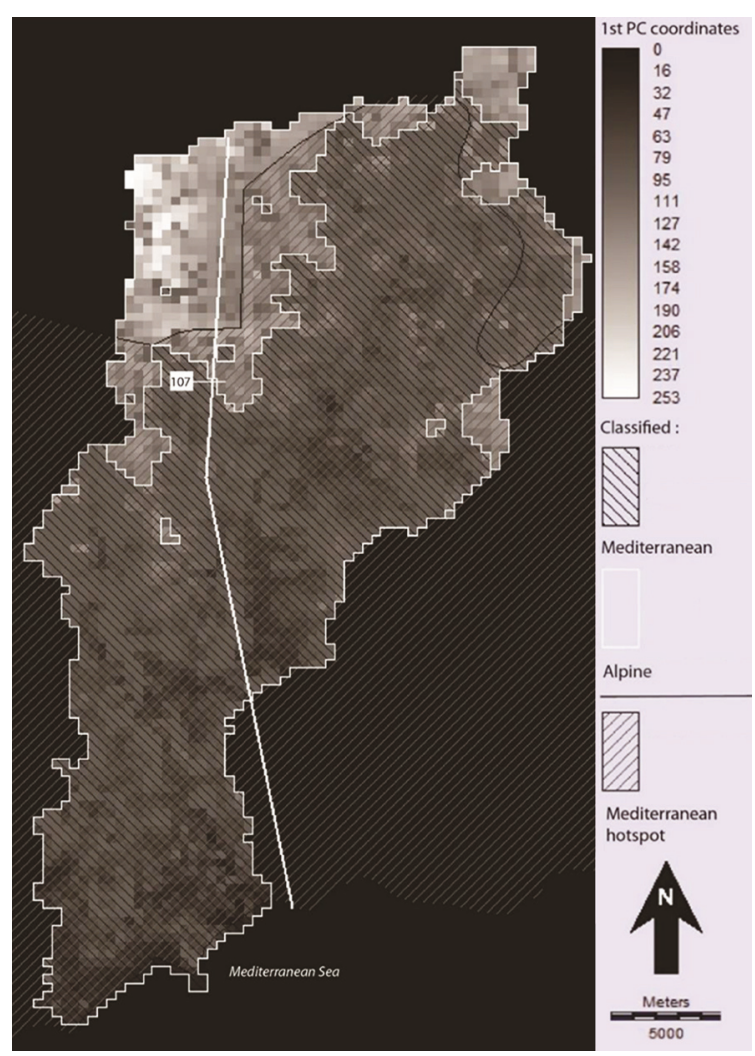

Figure 5. Classification of biogeographical areas and boundary of the Mediterranean hotspot.
Mediterranean species not crossing the line are very close, $54.3 \%$ on the transect and $52.6 \%$ on the grid. This limit, highlighted by the transect, should therefore be generalised, especially that of Mediterranean species, more than that of Alpine species.

The representativeness of the results is commensurate to the scale of the valley but it remains very large scale in relation to the Mediterranean biogeographical area. However, this grid analysis also made it possible to map the difference between this boundary and that of the Mediterranean hotspot. Although differences appear at this scale, as the Hotspot boundary is higher in the northwest and lower in the south-west, these boundaries are often only a few hundred meters and, at most, a few kilometers away from one another. This field campaign and the complementary analysis under a GIS validates very clearly the outline of the Mediterranean Hotspot, that can be downloaded as GIS dataset (www.cepf.net). However, we cannot broaden this spatial validation to sectors where the hotspot boundary lies in a plain. It can be assumed that the configuration described here is characteristic of the boundary of the Mediterranean area when it is in contact with the mountain flora of another biogeographical area.

\section{CONCLUSIONS}

The species boundaries between the Mediterranean and the Alps, an area where the climatic gradient is short, seem to be concentrated in a medium mountain sector at altitudes of around 1500 meters. A vast majority of Mediterranean affinity species end before this threshold and the Mediterranean region, thus delimited, is characterized by a fairly clear homogeneity. This significant limit, which appears on the transect on the adret side of Cairos river, could be generalized by a line separating the low and high areas of the study area. The renewal of the flora on either side of this line is $76 \%$ according to the transect. It amounts to $62 \%$ according to geomatics. This is a transition by depletion since less than a quarter of the species extends across this line and their limits are at varying distances from it. Samplings north of the line are characterized by relatively low richness. The breadth of the transition zone seems particularly reduced (a few hundred meters). 
The boundary of the hotspot and the boundary of the Mediterranean biogeographical area seem to converge well if one examines these lines on the macro-regional or global scale where the hotspot boundary was drawn. There are a few hundred meters of difference between the two lines, sometimes locating the hotspot, sometimes the area higher up.

\section{REFERENCES}

Alexandre F., 1994. Entre midis méditerranéen et atlantique, une transition phytoclimatique du Languedoc à l'Aquitaine. Thèse de doctorat Géographie Paris 7 Dir. Lecompte M., 428 pp.

Alexandre F., Génin A. \& Lecompte M., 1998a. Seuils biologiques et limites climatiques en Méditerranée occidentale. Géocarrefour: Revue de Géographie de Lyon, 73: 33-43.

Alexandre F., Génin A., Godron M. \& Lecompte M., 1998 B. Distribution des plantes et organisation de la végétation. L'Espace géographique, 27: 228-238.

Sophie Condé \& Dominique Richard (coordinators) 2002. Europe's biodiversity - biogeographical regions and seas. EEA, Copenhagen 2002 https://www.eea.europa.eu/publications/report_2002 _0524_154909

Cox B., 2001. The biogeographic regions reconsidered. Journal of Biogeography, 28: 511-523. https://doi. org/10.1046/j.1365-2699.2001.00566.x

Ferro I. \& Morrone J. J., 2014. Biogeographical Transition Zones. Biological Journal of the Linnean Society, 113: 1-12. https://doi.org/0.1111/bij.12333

Gao P. \& Kupfer J.A., 2018. Capitalizing on a wealth of spatial information: Improving biogeographic regionalization through the use of spatial clustering, Applied Geography, 99: 98-108. https://doi.org/10. 1016/j.apgeog.2018.08.002.

Génin A., 1995. Les contacts entre domaines phytoclimatiques. L'exemple de la bordure cévenole. Thèse de doctorat Géographie, Paris 7 Dir. Lecompte M.

Godet L. \& Devictor V., 2018, What conservation does. Trends in Ecology \& Evolution, 33: 720-730, https:// doi.org/10.1016/j.tree.2018.07.004.

Godron M. \& Andrieu J., 2013. Mise en évidence statistique d'un continuum à facettes le long d'un transect floristique dans les Baronnies. Actes du colloque Continu et discontinu dans l'espace géographique. Tours Novembre 2002. Maison des Sciences de 1'Homme. Presse Universitaires François Rabelais, 145-170

Good R., 1947. The Geography of Flowering Plants.
Longmans, Green and Co, New York, 516 pp.

Hattab T., Albouy C., Lasram F.B., Le Loc'h F., Guilhaumon F. \& Leprieur F., 2015. A biogeographical regionalization of coastal Mediterranean fishes. Journal of Biogeography, 42: 1336-1348 https://doi.org/10. 1111/jbi. 12505

Kier G., Mutke, J., Dinerstein E., Ricketts T.H., Küper W., Kreft H. \& Barthlott W., 2005. Global patterns of plant diversity and floristic knowledge. Journal of Biogeography, 32: 1107-1116. https://doi.org/10. 1111/j.1365-2699.2005.01272. x

Mackey B.G., Berry S.L. \& Brown T., 2008. Reconciling approaches to biogeographical regionalization: A systematic and generic framework examined with a case study of the Australian continent. Journal of Biogeography, 35: 213-229.

Médail F. \& Quezel P., 1997. Hot-Spots Analysis for Conservation of Plant Biodiversity in the Mediterranean Basin. Annals of the Missouri Botanical Garden, 84: 112-127. https://doi.org/10.2307/2399957

Médail F. \& Quezel P., 2003 Ecolgie et biogéographie des forêts du bassin méditerranéen. Editions scientifiques Elsevier, Collection environnement, 574 pp.

Molinos J.G., Poloczanska E.S., Olden J.D., Lawler J.J. \& Burrows M.T., 2018. Biogeographical Shifts and Climate Change. Dellasala D.A. \& Goldstein (Eds.), Encyclopedia of the Anthropocene, M.I. Elsevier, 217-228. https://doi.org/10.1016/B978-0-12- 809665 -9.09814-1.

Morrone J.J., 2018. The spectre of biogeographical regionalization. Journal of Biogeography, 45: 282 288. https://doi.org/0.1111/jbi.13135

Myers N., 1990. The biodiversity challenge: expanded hot spots analysis. The Environmentalist, 10: 243 256. https://doi.org/10.1007/BF02239720

Myers N., Mittermeir R.A., Mittermeir C.G., Da Fonseca G.A.B. \& Kent J., 2000. Biodiversity hotspots for conservation priorities. Nature, 403: 853-858. https:// doi.org/10.1038/35002501

Olson D.M., Dinerstein E., Wikramanayake E.D., Burgess N.D., Powell G.V.N., Underwood E.C., D'Amico J.A., Itoua I., Strand H.E., Morrison J.C., Loucks C.J., Allnutt T.F., Ricketts T.H., Kura Y., Lamoreux J.F., Wettengel W.W., Hedao P. \& Kassem K.R., 2001. Terrestrial ecoregions of the world: a new map of life on Earth. Bioscience, 51: 933-938. https: //doi.org/10.1641/0006-3568(2001)051[0933: TEO TWA]2.0.CO;2

Takhtajan A., 1986. Floristic Regions of the World (translated by T.J. Crovello \& A. Cronquist). University of California Press, Berkeley, 401 pp.

Whittaker R.H., 1967. Gradient analysis of vegetation. Biological Reviews, 42: 207-264. https://doi.org/0. 1111/j. 1469-185X.1967.tb01419.x 